\title{
ENHANCEMENT OF THE PERFORMANCE OF AN INDUSTRY BY THE APPLICATION OF TQM CONCEPTS
}

\author{
B. Ramreddy ${ }^{1}$, D. Choudhary ${ }^{2}$ \\ ${ }^{1}$ Asst.Prof, ${ }^{2}$ Prof, Mech Engg Dept, G.N.D. Engg, College Bidar, Karnataka, India \\ rsb15bid@gmail.com,ranjan_sudha123@yahoo.co.in
}

\begin{abstract}
Nowadays many companies are unable to prove their performance, because they do not practice the TQM concepts in-total. In order to increase the awareness, certain TQM techniques are suggested to enhance overall performance of the organisations. Here an effort is made to apply two important basic concepts of TQM which are i) continuous improvement of production process by applying newer and innovative methods ii)establishing performance measures for the processes. This paper uses the real experimental results of cartons making industry which comprises the four machines such as Printing , Punching, Gluer and Lamination machines. We get all the machines input and output details, and then made certain suggestions based on the input values of all the four machines. Presently the four machines output values such as Availability, Performance, Quality and Overall Equipment Effectiveness are very low compared with the world class industry. In order to increase them it is suggested to reduce the downtime and other non-productive time by adopting certain simple TQM techniques. The new improved values found to be much higher than the existing values.
\end{abstract}

Keywords: Total Quality Management, Availability, Performance, Quality, Overall Equipment Effectiveness, Quality Improvement.

\section{INTRODUCTION}

Today more than ever, the long-term survival of many manufacturing and service organizations is considered to be inextricably linked to the ability of these organizations to produce goods and services that meet or exceed customer's quality expectations [1]. Most organizations apply the Japanese methods of production and philosophies for achieving the required growth in the market for higher profits. One of the main ideas that came from the Japanese industry is Total quality management (TQM) [2], which is defined as an efficient quality enhancement approach for firm-wide management for the function of improving performance in terms of quality, productivity, customer satisfaction, and profitability [3].

It represents an integrative approach for organizations in the pursuit of continuous performance improvement and competitive advantage in both local and global markets [4]. TQM is a total system approach which works horizontally across functions and departments, involving all employees (top to bottom), the supply chain and customer chain [5]. The key components of TQM are customer focus, continuous improvement in products, processes and services, statistical measurement, benchmarking as well as the employee empowerment. More specific tools for quality improvement include for example, Pareto analysis, cause-and-effect diagrams, check sheets, and statistical process control charts [6].

Statistical process control (SPC) is one of the most effective approaches in TQM. The most essential aspect of implementing SPC is control charting. A process is out-ofcontrol when points fall outside the control limits and the control charts display unnatural (non-random) patterns [7]. When an anomalous variation is signaled by control chart, quality practitioners or engineers search for the assignable causes and take some crucial correction and adjustments to bring the out-of control process back to the normal state [8].Another parameter is Quality, which can be defined as meeting the legal, aesthetic and functional requirements of a project whereas in construction industry the quality is defined as meeting the requirements of the designer, constructor and regulatory agencies as well as the owner[9]. This entails a change in behavior and attitude which prioritizes the elimination of problems and their causes instead of simply focusing on their detection and separation. TQM promotes the involvement of everyone working together in a process of continuous improvement and in assuring product and service quality [10]. While the quality management concept and tools have been widely accepted in industries, various reports on the success and failure of their implementation have been noted, varying from well-documented anecdotal evidence to empirical studies [11].Hourly data system (HDS) is the real time view of production floor of any manufacturing company. 
Usually the operators of the machines give input of the produced volume every hour. It also provides the basic data for quality control (QC) analysis and Preventive Maintenance (PM) [12].

The TQM will be implemented based on the Critical Success Factors (CSFs) that is essential for the successful implementation of the tools in local organizations, (i.e.) Assessment of the relevant existing knowledge, formulation of the concepts and proportions, statement of hypothesis, design of research to test the hypothesis, meaningful data collection, analysis and evaluation of the data and conclusion of the factual findings [13]. Many researchers analyzed about the TQM, One of them told about it, (i.e.) "Any organization basically competes on its reputation for quality, reliability, price and delivery, and most people now recognize that quality is the most important of these competitive weapons" [14]. Employee performance is one of the parameter of TQM, which is used to determine the performance of different types of employees, by utilizing the shop floor data of logistic activities. The employee performance calculation estimates the operational performance of direct workers and indirect managers [15].In this paper, an effort is made to analyze and apply the TQM to one manufacturing company using multi objective evolutionary algorithm, which is one of the most active research areas in the field of evolutionary computation. A number of Evolutionary Multi Objective (EMO) algorithms have been proposed and successfully used in a wide range of real-world application tasks [16]. The Evolutionary algorithm includes Genetic Algorithm, Particle swarm optimization algorithm, Scatter Search algorithm, ABC algorithm etc. In this paper the real experimental results in carton making industry, which comprises the four machines are used as input with proposed model. Quality performance is the main factor of machine performance as well as industry performance. If the machine quality is in good condition We get the optimum result of products. If any problem arises in machine, it leads to failure, breakdown and make a huge cost as well as decrease the profit of an industry.

\section{RELATED WORKS}

In 2009, Marc Wouter [17] has developed an approach for Performance measuring system (PMS), based on a longitudinal case study with action research. The company has made enormous investments in operations, and it therefore needed PMS to facilitate improvement of processes and to measure the actual realization of the benefits from their investments. The company adopted a developmental approach for performance measurement which was based on experience, experimentation, building on employees' professionalism, transparency and employee ownership and outside facilitators. It resulted in extended set of new and well-founded measures, it has enhanced employee's beliefs in the PMS, their commitment to performance improvement and it has created organizational learning concerning to performance measurement.

In 2013, Jane M, Cramm et al. [18] has proposed to explore innovative cultures in Quality Improvement (QI) teams over time and identify its determinants. The study included, QI teams participating between 2006 and 2011 in a national Dutch quality program (Care for Better) using an adapted version of the Breakthrough Method. Each QI team member received a questionnaire by mail. They measured innovative culture, respondent characteristics (age, gender, and education), perceived team effectiveness, organizational support and management support. Multilevel analyses showed that perceived effectiveness, organizational support, and management support predicted innovative culture. Their QI teams were not able to improve innovative culture over time but their innovative culture scores were higher than nonparticipant professionals. QI interventions require organizational and management support to enhance innovative culture in long-term care settings.

In 2011, Richard Yu , Baiyin Yang et al. [19] have explained three main goals: (i) to determine the relationships between TQM, organizational learning, and innovation performance; (ii) to determine if organizational learning fosters innovation performance and plays a mediating role between TQM and innovation performance, and (iii) to test a proposed model explaining the relationships among TQM, organizational learning, and innovation performance through empirical examination. Using a self-administered survey to sample Taiwanese high-tech industry companies, their study examined four hypotheses and tests the proposed model. The principal findings of that study were as follows; (i) Structured Equation Modeling (SEM) analysis shows that the TQMorganizational learning innovation performance model has goodness-of-fit, (ii) TQM has significant and positive effects on organizational learning, and (iii) TQM and organizational learning have both significant and positive effects on innovation performance.

Over the past two decades, China has emerged as a global economic power, ranking behind only the USA, Japan and Germany. China's continuous global economic power has therefore prompted a surge in interest in understanding Chinese business practices. In 2011, Mathew Tsamenyi et al. [21] have reported on the results of a survey on the contingent relationship between business strategy, management control systems (MCS) and performance in Chinese Enterprises. The analysis was based on data gathered from 215 enterprises operating within the Xinjiang autonomous region of China. They also found that for those firms classified as pursuing a low cost strategy, the use of more financial based MCS had a positive effect on performance as suggested in the literature. Their research has implications for understanding management accounting practices in Chinese enterprises 


\section{METHODOLOGY AND FORMULAE USED}

The fundamental goal of a successful TQM technique in any corporation is its attention on the entire process of organization with a view to increase the quality, output, client delight and profitability. All these can be easily achieved if the employee is motivated utmost to outperform and the physical facilities are exploited to the optimum level. The subject matter of our discussion here centers on the element of optimum deployment of machinery leading to increase the quality, output, customer delight and profitability of the organization. The use of machinery is evaluated by OEE in the organizations. The Overall equipment effectiveness (OEE) is defined as the offshoot of Availability, Performance, and Quality and it is adversely affected by downtime. Downtime is defined as the duration of time during which system fails and incapacitated to execute elementary activities and is known by the term outage duration. To achieve effective decrease in downtime, the OEE value must be set so that losses can altogether be wiped off, thereby enhancing the profit of the company. In this regard, We have taken the concurrent data[22] of cartons making industry which uses four machine such as Printing machine, Punching Machine, Gluer Machine, Lamination Machine. We considered the output values of these machines[22], and propose to reduce downtime so as increase the total operating time therby increasing the availability(Availability=Total operating time/Total planned production time),performance (Performance $=$ Total pieces produced/operating time/production rate), quality(Quality=Total good pieces produced/Total pieces produced) and OEE (OEE $=$ Availability* Performance* Quality ). The obtained values are higher than those of existing values. With an eye on enhancing the output values, we have put forward certain proposals founded on the down time deviation, taking into consideration the fact that downtime is the chief factor influencing the complete procedure of the company. We will carry out changes in the downtime in accordance with the variance of each and every input constraint. The input constraints are total time(T), Machine downtime(D), Total operating time $\left(T_{t}\right)$, Total planned production time $\left(\mathrm{P}_{\mathrm{t}}\right)$, Production breaks(B),Production rate(R),Total no. of products produced(N), Total no. of products rejected(F),Total no. of high quality products produced $(\mathrm{G})$.Production breaks is set to default. Estimate certain input constraints according to the equation (1)\&(2)..

$$
\begin{gathered}
\mathrm{T}_{\mathrm{t}}=\mathrm{T}-\mathrm{D} \quad \ldots \ldots . . \\
\mathrm{P}_{\mathrm{t}}=\mathrm{T}-\mathrm{B} \quad \ldots . .
\end{gathered}
$$

The value of Total no. of pieces produced is the product of Total planned production time and production rate based on the actual performance value. The procedure is repeated to assess the input constraints of all machines. [Table 1 to 4] We obtain the optimum output value vis-à-vis that of the current technique.

\section{ANALYSIS AND GRAPHICAL EXPLANATION FOR DOWNTIME VARIATION}

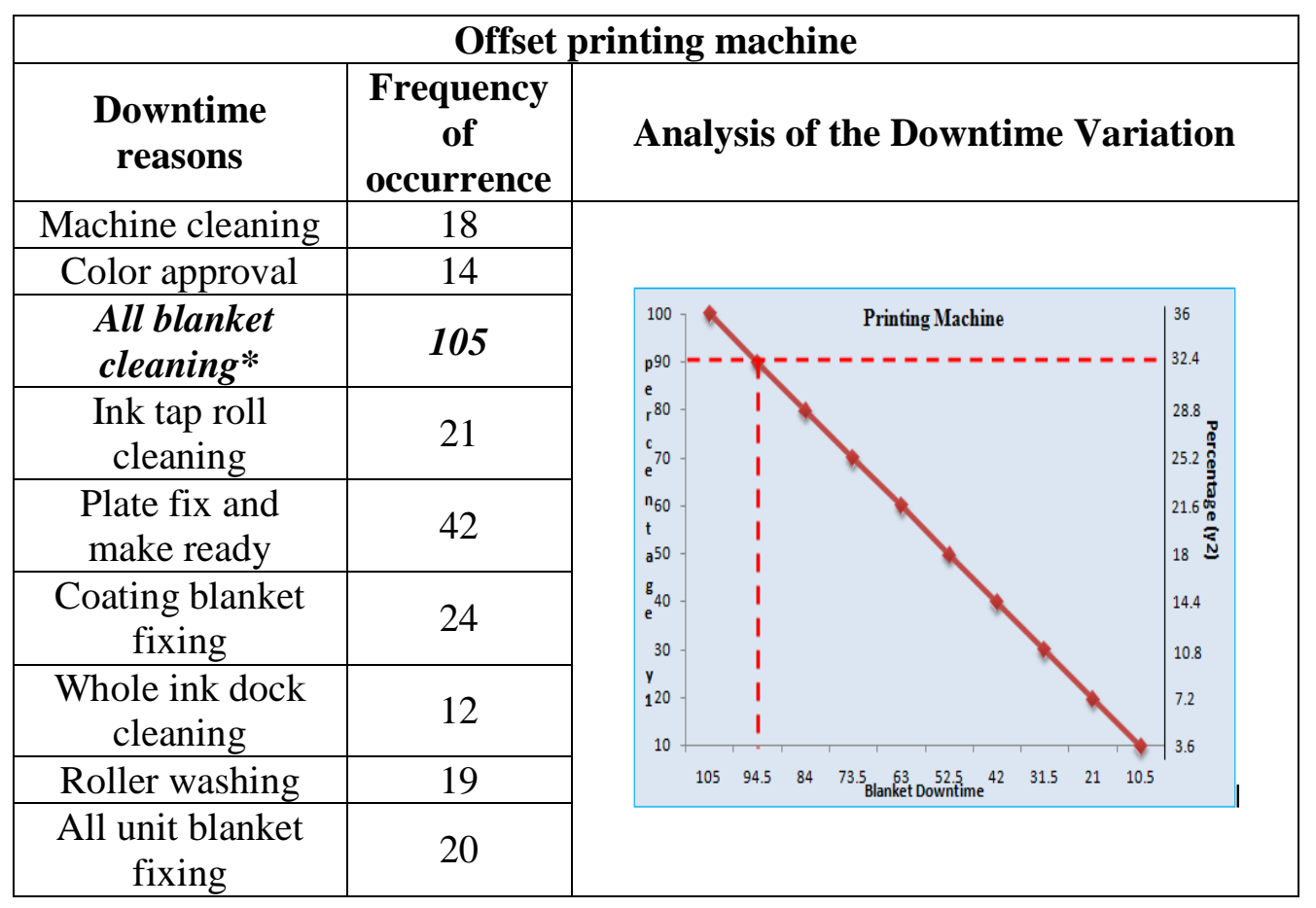




\begin{tabular}{|c|c|}
\hline Cylinder cleaning & 9 \\
\hline Roller change & 7 \\
\hline $\begin{array}{c}\text { Water change and } \\
\text { maintenance }\end{array}$ & 3 \\
\hline \multicolumn{2}{|c|}{ Total $=294$} \\
\hline
\end{tabular}

Fig1 Downtime variation of Printing Machine [22]

The fig(1) describes the variation of blanket cleaning process. Actually the blanket cleaning process is the one of the major time consuming and frequently needed process of downtime. As a innovative technique of process optimization and in order to rectify the process the new suggestion of introducing the twin turbo system for cleaning the printing machine (the*marked) downtime will be reduced automatically. Because it reduces the blanket cleaning process up to $90 \%$.It means the blanket cleaning process, in this present paper is attained to36\%(i.e 105/294 as shown above fig.1) out of $100 \%$ Downtime. Once the blanket cleaning process is reduced up to $90 \%$ periodically, which means the blanket cleaning can be done in $10 \%$ of $36 \%$ i.e. $3.6 \%$.
Therefore the total downtime in \%ge is $=(100-36)+(36-32.4)$ $=(64-3.6)=67.6=68($ approximated $)$

Therefore the downtime in min.(i.e.reduced downtime) = $255^{*} 68 \%=173 \mathrm{~min}$. which is tabulated in table (1)

The output which are expected are displayed in fig (1). The $\mathrm{x}$ axis represents as a variation of blanket cleaning process time and the y axis represents as the attainment of the result after down time variation considered as a $100 \%$. The secondary axis represented as a blanket cleaning process of $36 \%$, which is occurring from total down time.

\begin{tabular}{|c|c|c|c|c|}
\hline \multicolumn{5}{|c|}{ Punching Machine } \\
\hline $\begin{array}{l}\text { Downtime } \\
\text { reasons }\end{array}$ & $\begin{array}{c}\text { Frequency } \\
\text { of } \\
\text { occurrence }\end{array}$ & \multicolumn{3}{|c|}{ Analysis of the Downtime Variation } \\
\hline Sheet loading & 7 & \multirow{9}{*}{ 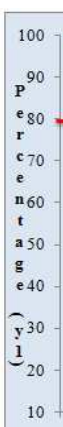 } & \multirow[t]{2}{*}{ Punching Machine } & \multirow{2}{*}{$\begin{array}{l}37 \\
33.3\end{array}$} \\
\hline Die setting & 31 & & & \\
\hline Cleaning & 17 & & & 29.6 \\
\hline No job* & 18 & & & \multirow{5}{*}{ 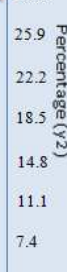 } \\
\hline Make ready* & 19 & & & \\
\hline Cutting correction & 2 & & & \\
\hline Two play cutting & 2 & & & \\
\hline Oiling & 1 & & & \\
\hline Die rubbing & 3 & \multirow{2}{*}{\multicolumn{3}{|c|}{ 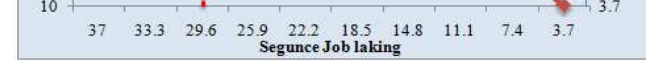 }} \\
\hline & Total $=100$ & & & \\
\hline
\end{tabular}

Fig2: Downtime variation of Punching Machine [22]

The fig (2) shows the process of punching machine according to the downtime variation. The $\mathrm{x}$ axis represented as a sequential job lacking. It is mentioned process of combining No Job and make ready process. It is occurred $37 \%$ (i.e. $37 / 100$ as shown above fig (2) of total down time process. In order to reduce the (*marked) downtime it is suggested to implement TQM techniques such as proper process planning and timely decision making process so that the downtime is automatically reduced considerably i.e. up to $80 \%$ as shown in fig.(2).

Therefore the total downtime in \%ge $=(100-37)+(37-$ 29.6) $=63+7.4=70.4$

Therefore the total downtime in min.(i.e reduced downtime $)=150 * 70 \%=105 \mathrm{~min}$. which is tabulated in table 2 


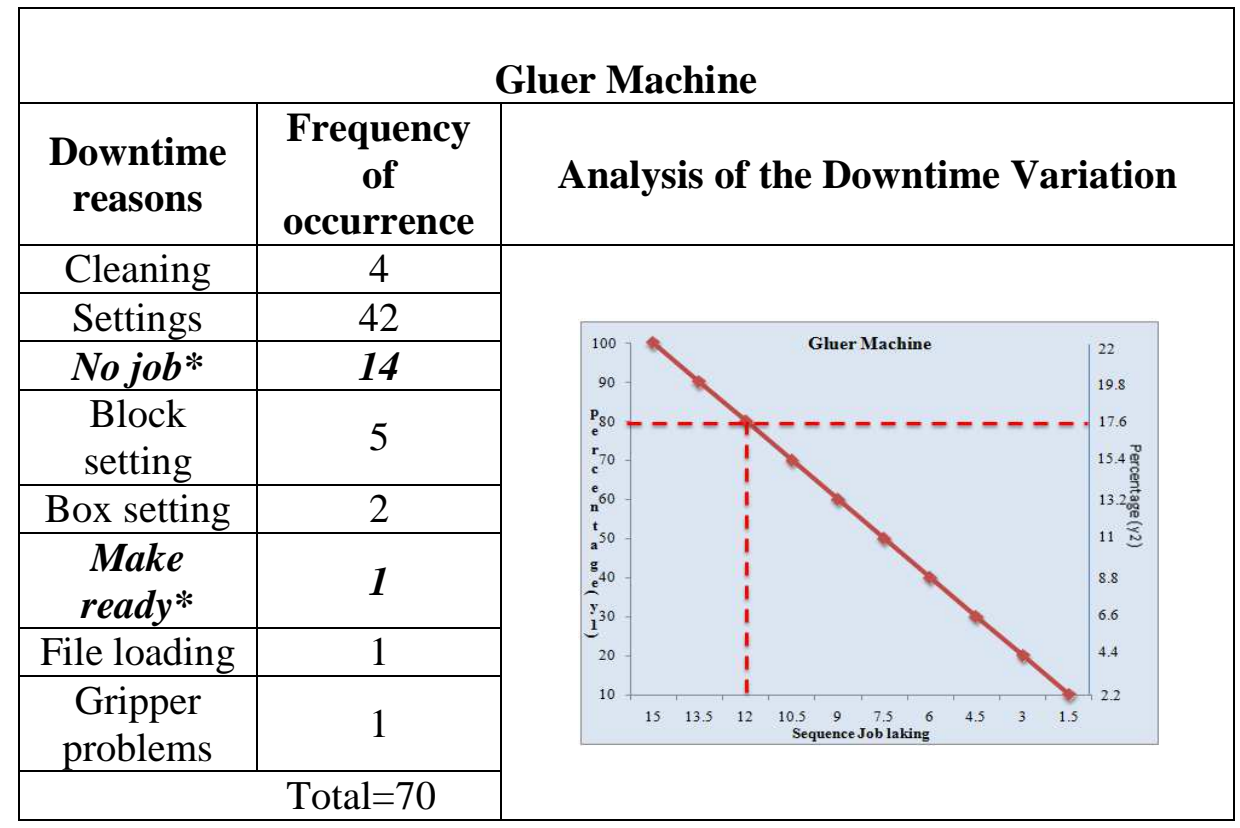

Fig3: Downtime variation of Gluer Machine [22]

This fig.(3) shows the process of Gluer machine according to the variation of one of the processes in the down time variation. The $\mathrm{X}$ axis represented as the sequence job lacking process of Gluer machine. The $\mathrm{Y}$ axis represents the result after down time variation considered as a $100 \%$. The secondary axis represented as the sequence job lacking process variation in the Total down time process. The sequence job lacking process consider as combining process of Make ready and No Job process. It is occurred $22 \%$ (i.e.15/70 as shown fig.3)from the total downtime process. In order to rectify the process we will implement the TQM in the organization. The proper planning and take suitable decision making process is one of the processes of the TQM. So we propose to implement these, the sequence job lacking process reduced up to $80 \%$.

Therefore the total downtime in \%ge $=(100-22)+(22-$ 17.6) $=78+4.4=82.4$

Hence the downtime in min.(i.e. reduced downtime $)=30 * 83 \%=25$ which is tabulated in table (3)

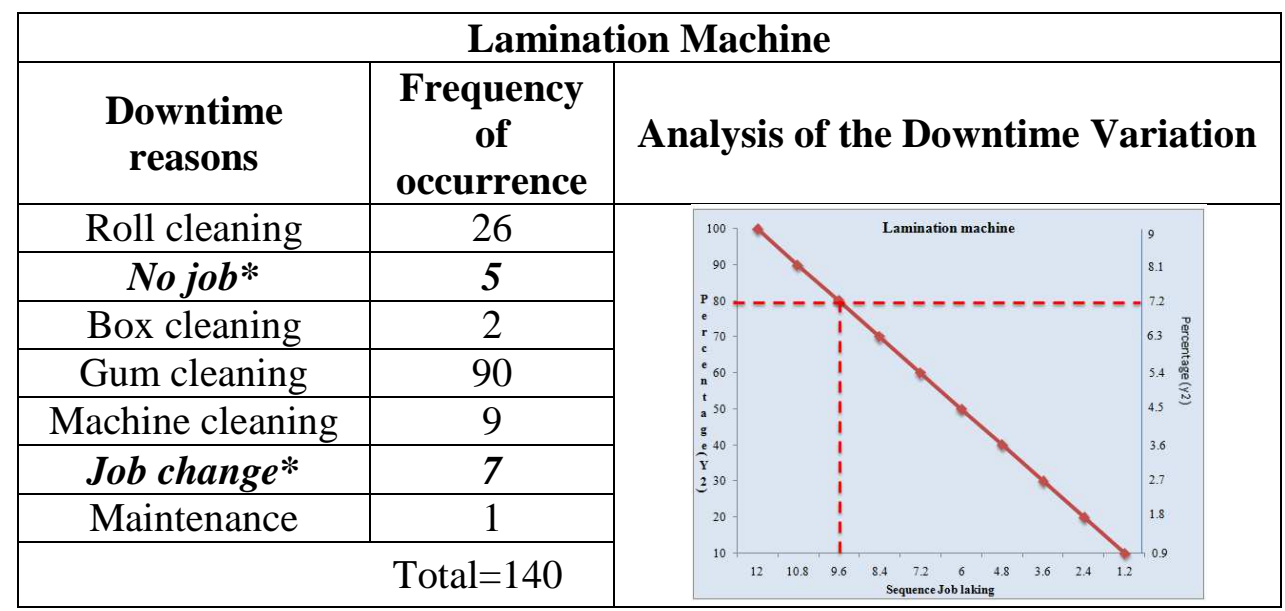

Fig4: Downtime variation of Lamination Machine [22] 
The fig.(4) shows the variation of one of the processes of down time process in Lamination machine. Actually the downtime is combination of the many processes. Here we consider the sequence job lacking processing in the total downtime process. It is the combination of No job and job changing process. In order to reduce these, we implement the TQM principles, so that the downtime is reduced easily. Here it is occurred 9\%( i.e.12/140 as shown above fig.4).We implement the proper planning and suitable decision making process in the company, the sequence job lacking process reduced up to $80 \%$.

Therefore the total downtime in $\%$ ge $=(100-9)+(9-$ $7.2)=91+1.8=93$ (approx).

Therefore the total downtime in min.(i.e reduced downtime $)=90 * 93 \%=84$ which is tabulated in table 4 .

\subsection{Suggested Techniques}

\subsubsection{Printing Machine}

The contemporary systems choose ordinary printing machine, and hence downtime is soaring as the blanket clean-up procedure take a lot of time. Many investigators have tried their level best to reduce the downtime of printing machine by the use of Twin turbo web cleaning system. Twin turbo web cleaning system performs the function of enhancing the yield of printing machine and reducing the cleaning procedure. It has many advantages - i) It reduces blanket cleaning periods; ii) It decreases damages on account of blanket cleaning; iii) It enlarges blanket life considerably; iv) It increases free press production time; v) It preserves print quality vi) makes the printing process stable; vii) It decreases rag and solvent (V.O.C.) usage and increases output. Hence the downtime gets reduced immediately. In the conventional method, the downtime was chiefly affected by the blanket cleaning procedure. The Twin turbo cleaning system is almost wiping off the blanket cleaning process. The blanket cleaning time usually consumes $36 \%$ in Total down time. The Twin turbo web cleaning system was executed and investigated by Tidningstryckarna Aftonbladet Svenska Dagbladet, a newspaper company located in swedan. We have evolved a new table. 1 based on a twin turbo web cleaning method which decreases the downtime up to 30 percentage. Consequently, the OEE value of printing machine reaches about $24.33 \%$ against the conventional printing machine OEE value of $16.67 \%$ [22]. The innovative method obtained $7.66 \%$ more OEE value than that of the conventional technique.

\section{Table 1: Suggested Results of Printing Machine}

\begin{tabular}{|c|c|c|c|c|c|c|c|c|c|c|}
\hline Production/shift & 1 & 2 & 3 & 4 & 5 & 6 & 7 & 8 & 9 & 10 \\
\hline Total time (Minutes) & 510 & 510 & 720 & 510 & 720 & 510 & 690 & 690 & 690 & 750 \\
\hline $\begin{array}{c}\text { Production Breaks } \\
\text { (minutes) }\end{array}$ & 30 & 30 & 30 & 30 & 30 & 30 & 0 & 0 & 0 & 30 \\
\hline $\begin{array}{c}\text { Machine } \\
\text { Downtime(minutes)* }\end{array}$ & $\mathbf{1 7 3}$ & $\mathbf{1 8 4}$ & $\mathbf{2 6 5}$ & $\mathbf{2 3 5}$ & $\mathbf{2 3 5}$ & $\mathbf{2 0 4}$ & $\mathbf{3 0 6}$ & $\mathbf{2 7 5}$ & $\mathbf{2 7 5}$ & $\mathbf{2 8 6}$ \\
\hline $\begin{array}{c}\text { Production Rate } \\
\text { (Unit/minute) }\end{array}$ & 266 & 266 & 266 & 266 & 266 & 266 & 266 & 266 & 266 & 266 \\
\hline $\begin{array}{c}\text { Total Cartoons Produced } \\
\text { Total Cartoons Rejected }\end{array}$ & 36830 & 27243 & 37872 & 26524 & 45507 & 47353 & 30439 & 42942 & 31461 & 70998 \\
\hline $\begin{array}{c}\text { Total Good Cartoons } \\
\text { Produced }\end{array}$ & 35357 & 26153 & 36357 & 25463 & 43687 & 45459 & 29221 & 41224 & 30203 & 68158 \\
\hline $\begin{array}{c}\text { Total planned production } \\
\text { time }\end{array}$ & 480 & 480 & 690 & 480 & 690 & 480 & 690 & 690 & 690 & 720 \\
\hline Total operating Time & 307 & 296 & 425 & 245 & 455 & 276 & 384 & 415 & 415 & 434 \\
\hline
\end{tabular}

\subsubsection{Punching Machine}

In the conventional a commonplace punching machine was used and the avg. OEE value got was $46.68 \%$ [22]. With a view to enhance the OEE value, we have to implement the TQM principles into company in future. The downtime got decreased by $30 \%$ compared to the current machine. Moreover OEE value raised to $59.28 \%$ an increase of $12.6 \%$ by our new technique over the current one 
Table 2: Suggested Result of Punching Machine

\begin{tabular}{|c|c|c|c|c|c|c|c|c|c|c|}
\hline Production/shift & 1 & 2 & 3 & 4 & 5 & 6 & 7 & 8 & 9 & 10 \\
\hline Total time (Minutes) & 480 & 480 & 510 & 510 & 510 & 510 & 510 & 510 & 510 & 510 \\
\hline $\begin{array}{l}\text { Production } \\
\text { (minutes) }\end{array}$ & 30 & 30 & 30 & 30 & 30 & 30 & 30 & 30 & 30 & 30 \\
\hline $\begin{array}{l}\text { Machine } \\
\text { Downtime(minutes)* }\end{array}$ & 105 & 210 & 273 & 210 & 242 & 147 & 158 & 74 & 53 & 63 \\
\hline $\begin{array}{ll}\text { Production } & \text { Rate } \\
\text { (Unit/minute) }\end{array}$ & 70 & 70 & 70 & 70 & 70 & 70 & 70 & 70 & 70 & 70 \\
\hline Total sheets Produced & 23184 & $\begin{array}{l}1622 \\
9\end{array}$ & $\begin{array}{l}1159 \\
2\end{array}$ & 5424 & $\begin{array}{l}2032 \\
5\end{array}$ & 25385 & $\begin{array}{l}1821 \\
2\end{array}$ & $\begin{array}{l}2523 \\
7\end{array}$ & $\begin{array}{l}2785 \\
7\end{array}$ & 21863 \\
\hline Total Sheets Rejected & 116 & 81 & 58 & 27 & 102 & 127 & 91 & 126 & 139 & 109 \\
\hline $\begin{array}{l}\text { Total Good Sheets } \\
\text { Produced }\end{array}$ & 23068 & $\begin{array}{l}1614 \\
8\end{array}$ & $\begin{array}{l}1153 \\
4\end{array}$ & 5397 & $\begin{array}{l}2022 \\
3\end{array}$ & 25258 & $\begin{array}{l}1812 \\
1\end{array}$ & $\begin{array}{l}2511 \\
1\end{array}$ & $\begin{array}{l}2771 \\
8\end{array}$ & 21754 \\
\hline $\begin{array}{l}\text { Total planned } \\
\text { production time }\end{array}$ & 450 & 450 & 480 & 480 & 480 & 480 & 480 & 480 & 480 & 480 \\
\hline Total operating Time & 345 & 240 & 207 & 270 & 238 & 333 & 322 & 406 & 427 & 417 \\
\hline
\end{tabular}

The Table 2 shows the suggested input data(*) of punching machine. Actually the punching machine used to make the demarcation of the cartons as per the requirements of the company. Mainly the punching machine used to produce the Good sheets of cartons in the company.

\subsubsection{Gluer Machine}

The conventional method uses the general gluer machine. The avg. OEE value was found to be $33.1 \%$ [22].In order to increase the OEE value; we will implement the TQM principles in the Organization. The down time is reduced up to
18\%. The TQM principles are suitably taking several measures such as Get organized, Pre-assemble Tooling and Forming Components, Record Set-Ups, Have the Right Parts for the job, Maintain your Machine, Don't be afraid to ask questions. In this regard, we have given shape to a novel suggestion table (3) which decreases the downtime by about $18 \%$, the OEE value finds jumped to $42 \%$, about $8.9 \%$ higher than the conventional technique

Table 3: Suggested Results of Gluer Machine

\begin{tabular}{|l|l|l|l|l|l|l|l|l|l|l|}
\hline Production/shift & 1 & 2 & 3 & 4 & 5 & 6 & 7 & 8 & 9 & 10 \\
\hline Total time (Minutes) & 510 & 510 & 720 & 510 & 510 & 750 & 840 & 510 & 510 & 630 \\
\hline $\begin{array}{l}\text { Production Breaks } \\
\text { (minutes) }\end{array}$ & 30 & 30 & 30 & 30 & 30 & 30 & 60 & 30 & 30 & 30 \\
\hline $\begin{array}{l}\text { Machine Rowntime(minutes)* } \\
\text { Dote }\end{array}$ & 25 & 271 & 295 & 172 & 148 & 98 & 418 & 197 & 344 & 172 \\
\hline $\begin{array}{l}\text { Production } \\
\text { (Unit/minute) }\end{array}$ & 350 & 350 & 350 & 350 & 350 & 350 & 350 & 350 & 350 \\
\hline $\begin{array}{l}\text { Total sheets Produced } \\
\text { Total Sheets Rejected }\end{array}$ & 552 & 1073 & 596 & 870 & 746 & 1540 & 2117 & 741 & 673 & 297 \\
\hline $\begin{array}{l}\text { Total Good Sheets } \\
\text { Produced }\end{array}$ & 49612 & 96509 & 53598 & 78255 & 67115 & 138441 & 190340 & 66613 & 60541 & 26667 \\
\hline $\begin{array}{l}\text { Total } \\
\text { production time }\end{array}$ & 480 & 480 & 690 & 480 & 480 & 720 & 780 & 480 & 480 & 600 \\
\hline Total operating Time & 455 & 209 & 395 & 308 & 332 & 622 & 362 & 283 & 136 & 428 \\
\hline
\end{tabular}




\subsubsection{Lamination Machine}

It is employed to safeguard the printed credentials. In the conventional method general lamination machine was used without giving details of the kind of machine. The avg.OEE value of conventional method is found to be $59.68 \%$ [22]. In order to enhance the OEE the TQM principles are implemented, The sequence job lacking process is reduced up to $80 \%$.Thus we have given shape to a novel table(4) according to downtime variation of the OEE value as per theoretical is $65.30 \%$. The downtime was only $7 \%$ compared to existing technique. Our suggested OEE value is $2.61 \%$ higher than the existing paper.

Table 4: Suggested Results of Lamination machine

\begin{tabular}{|l|l|l|l|l|l|l|l|l|l|l|}
\hline Production/shift & 1 & 2 & 3 & 4 & 5 & 6 & 7 & 8 & 9 & 10 \\
\hline $\begin{array}{l}\text { Total time } \\
\text { (Minutes) }\end{array}$ & 510 & 510 & 510 & 510 & 510 & 510 & 660 & 480 & 690 & 1020 \\
\hline $\begin{array}{l}\text { Production Breaks } \\
\text { (minutes) }\end{array}$ & 30 & 30 & 30 & 30 & 30 & 30 & 30 & 30 & 30 & 60 \\
\hline $\begin{array}{l}\text { Machine } \\
\text { Downtime(minutes } \\
\text { )* }\end{array}$ & 84 & 112 & 84 & 251 & 56 & 223 & 112 & 28 & 84 & 112 \\
\hline $\begin{array}{l}\text { Production Rate } \\
\text { (Unit/minute) }\end{array}$ & 26 & 26 & 26 & 26 & 26 & 26 & 26 & 26 & 26 & 26 \\
\hline $\begin{array}{l}\text { Total cartoons } \\
\text { Produced Cartoons }\end{array}$ & 7022 & 7951 & 8772 & 4692 & 8753 & 5780 & 9751 & 9195 & 12131 & 15742 \\
\hline $\begin{array}{l}\text { Total Good } \\
\text { Rejected }\end{array}$ & 6945 & 7864 & 8676 & 4640 & 8657 & 5716 & 9644 & 9094 & 11998 & 15569 \\
\hline $\begin{array}{l}\text { Total } \\
\text { Cartoons Produced }\end{array}$ & 48 & 480 & 480 & 480 & 480 & 480 & 630 & 450 & 660 & 960 \\
\hline $\begin{array}{l}\text { Total planned } \\
\text { production time }\end{array}$ & 480 & 96 & 52 & 96 & 64 & 107 & 101 & 133 & 173 \\
\hline $\begin{array}{l}\text { Total operating } \\
\text { Time }\end{array}$ & 396 & 368 & 396 & 229 & 424 & 257 & 518 & 422 & 576 & 848 \\
\hline
\end{tabular}

The table 4 shows the suggested input data (*) of Lamination machine. Actually the Lamination machine used for the cartons picture sheet is pasted on the cardboard as per customer requirements in company. The company efficiency was verified by OEE values. If the OEE values are attained to $85 \%$, then the company is considered as a world class company.

\subsection{Real Experimental Modeling}

The table: 5 show the comparison of two results of s real experimental and the suggested one..Here we have taken only one shift data for calculations out of total ten shifts data. The data chosen are such that of higher values among all ten shifts, w.r.t. printing $\mathrm{m} / \mathrm{c}$ we considered data for calculation of Availability, Performance, Quality and OEE from the shifts 1,6,6 and 10 respectively. The input parameters of printing machine named as Total time (Minutes), Production Breaks (minutes), Machine Downtime (minutes), Production Rate (Unit/minute), Total Cartoons Produced, Total Cartoons Rejected, Total Good Cartoons Produced, Total planned production time, Total operating Time. These values are taken from the real experimental tabular column1..We will use real experimental values for finding the suggested output values. Let us see for example the Availability 1st observation of real experimental value and suggested result are 46.92 and 63.95 respectively. The company efficiency is verified by OEE values. If the OEE values are attaining the $85 \%$, the company considered as a world class company. But for printing machine the avg.OEE value is $16 \%$ in existing paper [22]. In order to increase the OEE value, we made a new suggestion table based on the down time variation Table 1. Our suggested method output values such as Availability, Performance, Quality and OEE. are higher and are shown in table 5. The suggested results of all machines output values are high compared to the existing results.

\subsection{Graphical Explanation of Comparison}

As we used only one shift data for presentation and analysis (Table5) The graphical presentation is made for all the machines data for all the four values/results 
Table 5: Final results of All Machines

\begin{tabular}{|l|l|l|l|l|l|}
\hline \multicolumn{1}{|c|}{$\mathrm{m} / \mathrm{c}$} & & $\begin{array}{l}\text { Printing m/c } \\
\text { (shift no.) }\end{array}$ & Punching m/c(shift no.) & $\begin{array}{l}\text { Gluer m/c } \\
\text { (shift no.) }\end{array}$ & $\begin{array}{l}\text { Lamination } \\
\mathrm{m} / \mathrm{c}(\text { shift no.) }\end{array}$ \\
\hline Availability(\%) & Real & $46.9211(1)$ & $84.3665(9)$ & $93.8116(1)$ & $93.2054(8)$ \\
\cline { 2 - 6 } & Suggested & $63.95833(1)$ & $88.9583(9)$ & $94.79167(1)$ & $93.7777(8)$ \\
\hline \multirow{2}{*}{ Performance(\%) } & Real & $64.5436(6)$ & $108.85(6)$ & $133.373(2)$ & $86.524(6)$ \\
\cline { 2 - 6 } & Suggested & $64.9(6)$ & $109.6(6)$ & $135(2)$ & $88.1(6)$ \\
\hline \multirow{2}{*}{ Quality(\%) } & Real & $96.0905(6)$ & $99.594(3)$ & $98.9931(9)$ & $98.992(1)$ \\
\cline { 2 - 6 } & Suggested & $97.02(6)$ & $99.9(3)$ & $99.6(9)$ & $99.3(1)$ \\
\hline \multirow{2}{*}{ OEE(\%) } & Real & $24.5765(10)$ & $78.29(9)$ & $51.97(7)$ & $77.3727(8)$ \\
\cline { 2 - 6 } & Suggested & $36.6554(10)$ & $84.044(9)$ & $70.680(7)$ & $78.999(8)$ \\
\hline
\end{tabular}

In order to see the fig.5, (which is self explanatory) the output results of four machines such as Availability, Performance, Quality, and OEE which exploits the comparison of real (original) results with the suggested (improved) results of each output parameter of each machine. In overall our suggested model results are always higher than the actual results.

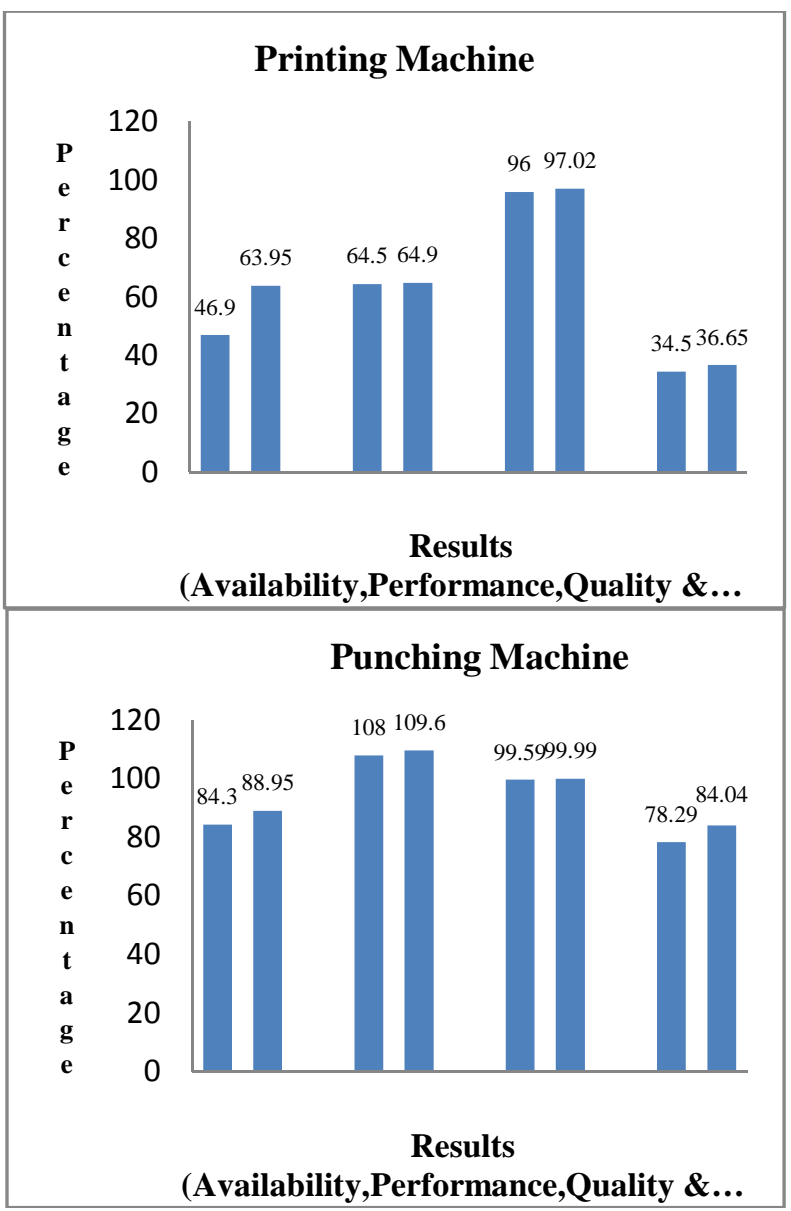

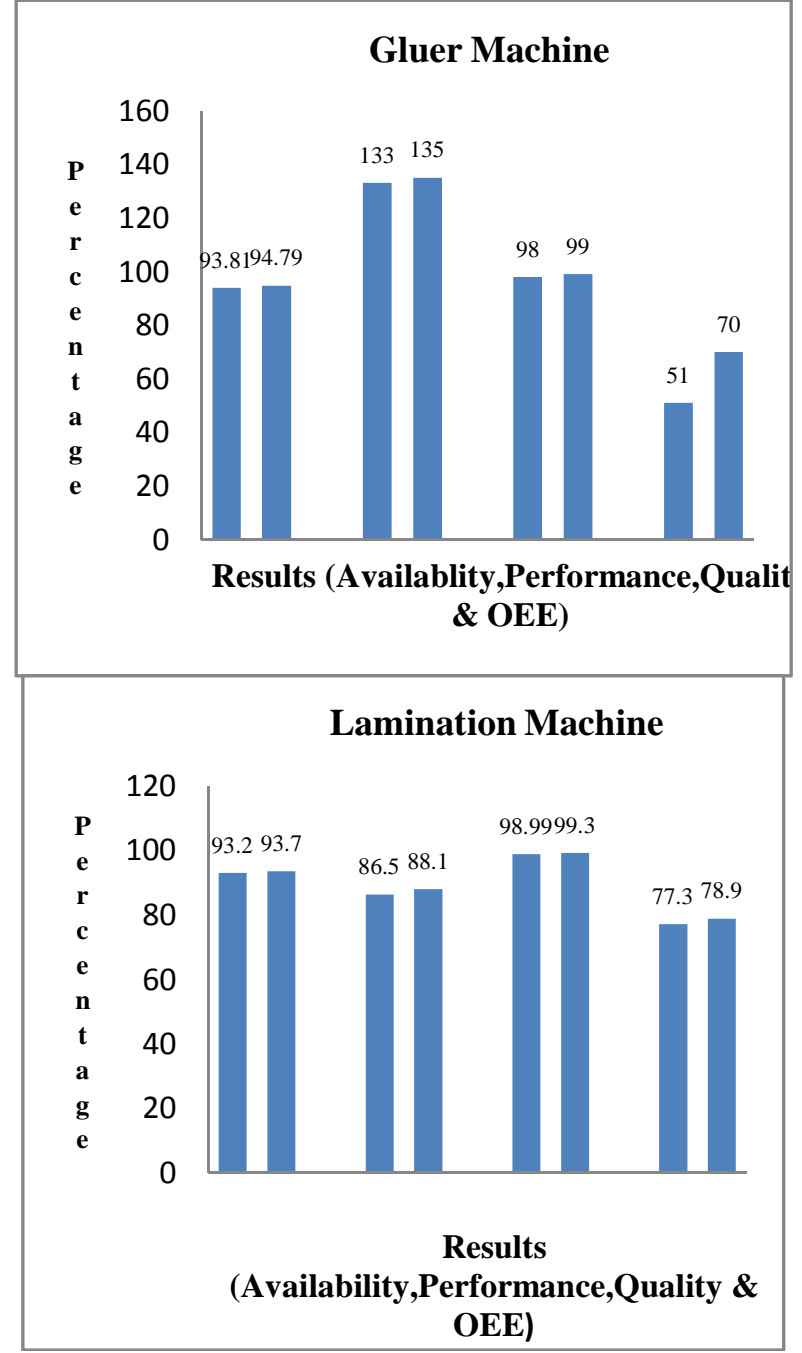

Fig 5: Comparison of Final Results (all four machines) 


\section{CONCLUSIONS}

In this paper an effort is made to analyze and implement certain TQM principles to enhance OEE. It is ascertained here that the smaller and simpler TQM concepts which are generally ignored or neglected can also contribute to a larger benefits of the organizations. For all the four machines printing, punching, glueing and lamination the existing average results OEE (\%) were $16.67 \%, 46.68 \%, 33.1 \%$ and $59.68 \%[22]$ respectively. The new final suggested average results of OEE (\%) values of four machines are $24.33 \%$, $59.28 \%, 42 \%$ and $62.29 \%$.respectively. These values are higher compared to the existing results(Fig.5)

\section{REFERENCES}

[1] Isaiah O.Ugboro and Kofi Obeng, "Top Management Leadership, employee empowerment, job satisfaction, and customer satisfactions in TQM organizations: an empirical study",The Journal of Quality management, Vol.5, pp.247272,2000 .

[2] Salman D. Al-Shobaki , Rami H. Fouad and Adnan AlBashir, "The Implementation of Total Quality Management (TQM) for The Banking Sector in Jordan", Jordan Journal of Mechanical and Industrial Engineering, Vol.4, No.2,pp.304313, March. 2010.

[3] Esin Sadikoglu and CemalZehir, "Investigating the effects of innovation and employee performance on the relationship between total quality management practices and firm performance: An empirical study of Turkish firms", International Journal of Production Economics, Vol.127,pp.13-26,2010.

[4] Senda Wali and Younes Boujelbene, "Cultural Influences on TQM Implementation and Financial Performance in Tunisian Firms", Journal of Economic and Management, Vol.3, pp.30-45, 2011

[5] Faisal Talib, Zillur Rahman and M.N. Qureshi, "A study of total quality management and supply chain management practices", International Journal of Productivity and Performance Management, Vol. 60,No.3,pp. 268-288, 2011

[6] Abdelkader Daghfous and Reza Barkhi, "The strategic management of information technology in UAE hotels:An exploratory study of TQM, SCM, and CRM implementations", Journal of Technovation, Vol.29,pp.588595,2009 .

[7] Ruey-Shiang Guh, "A hybrid learning-based model for online detection and analysis of control chart patterns", Journal of Computers \& Industrial Engineering, Vol.49, pp. 35-62, 2005.

[8]s Jian-bo Yu and Li-feng Xi, "A neural network ensemblebased model for on-line monitoring and diagnosis of out-ofcontrol signals in multivariate manufacturing processes", Journal of Expert Systems with Applications, Vol.36,pp.909921,2009

[9] Muhammad Asim ,Sohaib uz Zaman and Tayyaba Zarif, "Implementation of Total Quality Management in
Construction Industry: A Pakistan Perspective", Journal of Management and Social Sciences, Vol. 9, No. 1, pp.2439,2013

[10] Javier GonzaH lez-Benito and Barrie Dale, "Supplier quality and reliability assurance practices in the Spanish auto components industry: a study of implementation issues", European Journal of Purchasing \& Supply Management, Vol. 7, pp. 187-196,2001.

[11] VieraWardhania, Adi Utarinib, Jitse Pieter van Dijk ,Doeke Post and Johan Willem Groothoff, "Determinants of quality management systems implementation in hospitals", Journal of Health Policy, Vol. 89,pp.239-251,2009

[12] Farzana Sultana,Nahid Islam Razive and Abdullahil Azeem, "Implementation Of Statistical Process Control (Spc) For Manufacturing Performance Improvement" , Journal of Mechanical Engineering, Vol.40, No. 1,pp.15-21,June 2009

[13] S.Sivakumar and K.Muthusamy, "Critical Success Factors in Six Sigma Implementation- A Case Study of MNCs in Malaysia", In proceeding of IEEE International Conference on Quality and Reliability (ICQR),pp.536-540,2011.

[14] Dirk van Dyk and Leon Pretorius, “A System Dynamics Approach to Quality Improvement Programs in a Heavy Engineering Manufacturing Environment: A Case Study", In Proceedings of PICMET '12 of Technology Management for Emerging Technologies, pp. 3287-3296,2012

[15] Yu-Jen Wu and Jiang-Liang Hou, "An employee performance estimation model for the logistics industry", Journal of Decision Support Systems, Vol.48,pp.568581,2010

[16] Hisao Ishibuchi, Noritaka Tsukamoto and Yusuke Nojima, "Evolutionary Many-Objective Optimization: A Short Review", In Proceeding of IEEE Congress on Evolutionary Computation, pp. 2424-2431, Hong Kong, June 1-6, 2008.

[17] Marc Wouters, "A developmental approach to performance measures-Results from a longitudinal case study", Journal of European Management Vol.27,pp.6478,2009 .

[18] Jane M. Cramm, Mathilde M.H. Strating, Roland Bal, Anna P. Nieboer, "A large-scale longitudinal study indicating the importance of perceived effectiveness, organizational and management support for innovative culture", Journal of Social Science \& Medicine, Vol.8,pp.119-124,2013.

[19] Richard Yu Yuan Hung , Bella Ya-Hui Lien, Baiyin Yang, Chi-Min Wu and Yu-Ming Kuo, "Impact of TQM and organizational learning on innovation performance in the hightech industry", Journal of International Business Review,Vol.20,pp.213-225,2013

[20] Y.K. Leung, K.L. Choy and C.K. Kwong, "A real-time hybrid information-sharing and decision support system for the mould industry", Journal of High Technology Management Research, Vol.21,pp.64-77,2010.

[21] Mathew Tsamenyi, Sunil Sahadev and Zheng Shi Qiao, "The relationship between business strategy, management control systems and performance: Evidence from China”, 
Journal of Advances in Accounting, incorporating Advances in International Accounting, Vol.27,pp. 193-203,2011

[22] Pradeep Kumar, K. V. M. Varambally and Lewlyn L.R. Rodrigues, "A Methodology for Implementing Total Productive Maintenance in Manufacturing Industries-A Case Study", International Journal of Engineering Research and Development,Vol.5,No.2,pp. 32-39,2013.

\section{BIOGRAPHIES}

B. Ramreddy is working as faculty in Mechanical Engg. Dept. G.N.D. Engg. College Bidar, Karnataka. The area of interest is quality Engg. Operation research, ergonomics etc 